\title{
Do Asian Patients Require Only Half of the Clozapine Dose Prescribed for Caucasians? A Critical Overview
}

\author{
Jose de Leon ${ }^{1,2}$, Anto P. Rajkumari,4, Arun R. Kaithi ${ }^{5}$, Georgios Schoretsanitis ${ }^{6}$, John M. Kane ${ }^{6,7}$, \\ Chuan-Yue Wang ${ }^{8}$, Yi-Lang Tang ${ }^{9}$, Shih-Ku Lin ${ }^{10}$, Kyung Sue Hong ${ }^{11}$, Saeed Farooq ${ }^{12}$, Chee H. Ng$^{13}$, \\ Can-Jun Ruan ${ }^{14}$, Chittaranjan Andrade ${ }^{15}$
}

\begin{abstract}
Since 1997, studies have found that Asians need lower clozapine doses than Caucasians. Caucasians with average clozapine metabolism may need from 300 to $600 \mathrm{mg} /$ day to reach the therapeutic range $(350 \mathrm{ng} / \mathrm{ml})$. Thus, serum clozapine concentration-to-dose (C/D) ratios typically range between 0.60 (male smokers) and 1.20 (female non-smokers). A 2019 systematic review of clozapine levels demonstrated weighted mean C/D ratios of 1.57 in 876 East Asians and 1.07 in 1147 Caucasians $(P<.001)$. In Asian countries, average clozapine doses are lower than $300 \mathrm{mg} / \mathrm{day}$. After sex and smoking stratification in 5 Asian samples with clozapine concentrations, the clozapine dose required to reach $350 \mathrm{ng} / \mathrm{ml}$ in female non-smokers ranged from 145 to $189 \mathrm{mg} /$ day and in male smokers, from 259 to $294 \mathrm{mg} / \mathrm{day}$. Thus, in Asian patients with
\end{abstract}

\begin{tabular}{|l|c|}
\hline \multicolumn{2}{|c|}{ Access this article online } \\
\hline \multirow{2}{*}{ Website: } & Quick Response Code \\
www.ijpm.info & \\
\hline & \\
DOI: & \\
10.4103/IJPSYM.IJPSYM_379_19 & \\
\end{tabular}

\begin{abstract}
This is an open access journal, and articles are distributed under the terms of the Creative Commons Attribution-NonCommercial-ShareAlike 4.0 License, which allows others to remix, tweak, and build upon the work non-commercially, as long as appropriate credit is given and the new creations are licensed under the identical terms.

For reprints contact: reprints@medknow.com

How to cite this article: de Leon J, Rajkumar AP, Kaithi AR, Schoretsanitis G, Kane JM, Wang CY, et al. Do asian patients require only half of the clozapine dose prescribed for caucasians? A critical overview. Indian J Psychol Med 2020;42:4-10.
\end{abstract}

\footnotetext{
${ }^{1}$ Mental Health Research Center, Eastern State Hospital, Lexington, Kentucky, USA, ${ }^{2}$ Psychiatry and Neurosciences Research Group (CTS-549), Institute of Neurosciences, University of Granada, Granada, Spain, and Biomedical Research Centre in Mental Health Net (CIBERSAM), Santiago Apóstol Hospital, University of the Basque Country, Vitoria, Spain, ${ }^{3}$ Department of Psychiatry, Christian Medical College, Vellore, Tamil Nadu, India, ${ }^{4}$ Institute of Mental Health, University of Nottingham, Nottingham, United Kingdom, ${ }^{5} \mathrm{Hazelwood}$ Center, Louisville, Kentucky, ${ }^{6}$ Department of Psychiatry, Zucker Hillside Hospital, Northwell Health, Glen Oaks, ${ }^{7}$ Department of Psychiatry and Molecular Medicine, Donald and Barbara Zucker School of Medicine at Hofstra/Northwell, Hempstead, New York, USA, ${ }^{8}$ Department of Psychiatry, The National Clinical Research Centre for Mental Disorders and Beijing Key Lab of Mental Disorders and Beijing Institute for Brain Disorders Center of Schizophrenia, Beijing Anding Hospital, Capital Medical University, Beijing, China, ${ }^{9}$ Department of Psychiatry and Behavioral Sciences, Emory University School of Medicine, Atlanta, Georgia, and Substance Abuse Treatment Program, Atlanta VA Medical Center, Decatur, Georgia, USA, ${ }^{10}$ Department of General Psychiatry, Taipei City, Psychiatric Center, Taipei, Taiwan, and Department of Psychiatry, School of Medicine, Taipei Medical University, Taipei, Taiwan, ${ }^{1}$ Department of Psychiatry, Sungkyunkwan University School of Medicine, Samsung Medical Center, Seoul, Korea, ${ }^{12}$ School of Primary, Community and Social Care, Faulty of Medicine and Health Sciences, Keele University, Staffordshire, and Midlands Partnership NHS Foundation Trust, Staffordshire, United Kingdom, ${ }^{13}$ Department of Psychiatry, The Melbourne Clinic and St Vincent's Hospital, The University of Melbourne, Melbourne, Victoria, Australia, ${ }^{14}$ Laboratory of Clinical Psychopharmacology \& The National Clinical Research Centre for Mental Disorders \& Beijing Key Lab of Mental Disorders, Beijing Anding Hospital, Capital Medical University, Beijing, China, ${ }^{15}$ Department of Psychopharmacology, National Institute of Mental Health and Neurosciences, Bengaluru, Karnataka, India

Address for correspondence: Dr. Jose de Leon

Room 3A15A, Mental Health Research Center, Eastern State Hospital, 1350 Bull Lea Road, Lexington, Kentucky 40511, USA.

E-mail: jdeleon@uky.edu

Received: 08 ${ }^{\text {th }}$ September, 2019, Revision: $24^{\text {th }}$ September, 2019, Accepted: 07 ${ }^{\text {th }}$ October, 2019, Publication: $06^{\text {th }}$ January, 2020.
} 
average metabolism (with no inducers other than smoking, with no inhibitors, and in the absence of extreme obesity), the dose needed for clinical response may range between $150 \mathrm{mg} /$ day for female non-smokers to $300 \mathrm{mg} /$ day for male smokers. Clozapine levels may help personalize dosing in clozapine poor metabolizers (PMs) and ultrarapid metabolizers (UMs). Asian PMs may need very low doses (50-150 mg/day) to obtain therapeutic concentrations. About 10\% (range 2-13\%) of Asians are genetic PM cases. Other PMs are patients taking CYP1A2 inhibitors such as fluvoxamine, oral contraceptives, and valproate. Temporary clozapine PM status may occur during severe systemic infections/inflammations with fever and C-reactive protein (CRP) elevations. Asian UMs include patients taking potent inducers such as phenytoin, and rarely, valproate.

Key words: Asian continental ancestry group/genetics, blood, CYP1A2, clozapine, drug labeling, India, pharmacokinetics, sex, smoking

This review article proposes that the clozapine package insert (or drug labeling) and psychiatric literature should inform physicians that Asian patients with average clozapine metabolism are likely to need between 150 and $300 \mathrm{mg} /$ day of clozapine to reach therapeutic concentrations, in contrast with Caucasian patients with average clozapine metabolism who need 300 to $600 \mathrm{mg} /$ day.

\section{WHAT IS THE EVIDENCE?}

A reader familiar with United States psychiatric textbooks ${ }^{[1]}$ or review articles ${ }^{[2]}$ or British textbooks ${ }^{[3]}$ or guidelines ${ }^{[4]}$ may find the title of this article surprising. A British textbook ${ }^{[3]}$ states, "The range [for clozapine dosing] is approximately $250 \mathrm{mg} /$ day (female non-smoker) to $550 \mathrm{mg} /$ day (male smoker)" and makes no reference to Asian patients.

Average response in randomized clinical trials (RCTs) is used by pharmaceutical companies to provide recommended average doses, but this approach is misguided when statistical heterogeneity is present and when the mean does not represent the heterogeneous sample well. ${ }^{[5]}$ As a matter of fact, the question asked in a Cochrane review, "What is the optimal dose for clozapine in schizophrenia?"[6] is an irrelevant question because there is no average clozapine dose that is "best". The right dose depends on the clozapine clearance of the individual patient, which is mainly mediated by CYP1A2 and is significantly influenced by ethnicity, smoking status and sex, all of which have major influence on CYPlA2 activity. ${ }^{[7]}$ A better question therefore is to ask what dose is optimal for specific sub-groups: 1) Asian non-smoker females, 2) Asian non-smoker males, 3) Asian smoker females, 4) Asian smoker males, 5) non-Asian non-smoker females, 6) non-Asian non-smoker males, 7) non-Asian smoker females, and 8) non-Asian smoker males. ${ }^{[8]}$

These questions are at the heart of clinical practice but were not asked when clozapine was introduced in the market. Traditionally, drug studies for approval focused on Caucasian subjects, predominantly male, but this state of affairs is no longer satisfactory. The current need is to understand how different racial and ethnic ancestry can lead to differences in efficacy and safety in the use of various drugs.

\section{WHO ARE ASIANS?}

According to the Food and Drug Administration (FDA), the Asian phenotype includes people whose ancestral origins range geographically from Pakistan to Japan. ${ }^{[9]}$ Within that group is a more homogeneous genetic group called East Asians, who comprise of Chinese, Korean, Japanese, and Mongolian people. This classification is largely driven by the history of genetic evolution. ${ }^{[10]}$ This means that people from Western Asia $^{[11]}$ are genetically different from other Asians and are closer to Caucasian Europeans; ${ }^{[10]}$ it also means that the original people from the Americas ${ }^{[10]}$ have actually descended from East Asians and are likely to be genetically close to East Asians. In this review, we report clozapine levels from Vellore, which probably reflects a population from Southern India, while the Northern India population probably includes a more complex mix. ${ }^{[12]}$

\section{THE EVIDENCE FROM CLOZAPINE BLOOD LEVELS}

Although clozapine prescribers in Western countries are not aware that Asians need lower clozapine doses, this is not a new concept. In 1997, Chang et al. ${ }^{[13]}$ and Chong et al..$^{[14]}$ showed that Chinese patients who used half the clozapine dosage had concentrations similar to Caucasians. Moreover, in 2005, $\mathrm{Ng}$ et al. ${ }^{[15]}$ found that 20 Singaporean Asians (from 3 ethnic groups: Chinese, Indian, and Malay) had higher clozapine concentration-to-dose (C/D) ratios than 20 Australian Caucasians. 
The clozapine C/D ratio is a measure of clozapine drug clearance, which can be influenced by genetic, personal, and environmental factors. ${ }^{[16]}$ The clozapine $\mathrm{C} / \mathrm{D}$ ratio can be used to distinguish patients based on clozapine metabolism. Thus, patients with a very low clozapine C/D ratio belong to an ultrarapid metabolizer (UM) phenotype, while those with a very high $\mathrm{C} / \mathrm{D}$ ratio belong to a poor metabolizer (PM) phenotype. In 2015, a review ${ }^{[16]}$ proposed that in US schizophrenia patients, Caucasians with average clozapine metabolism usually need 300-600 mg/day to reach the lowest part of the therapeutic range $(350 \mathrm{ng} / \mathrm{ml})$. US male smokers usually reach a therapeutic concentration of $\geq 350 \mathrm{ng} / \mathrm{ml}$ with a dosage of $600 \mathrm{mg} /$ day; this corresponds to a C/D ratio of $0.58(350 / 600)$. US female non-smokers usually reach a concentration of $\geq 350 \mathrm{ng} / \mathrm{ml}$ with a dosage of only $300 \mathrm{mg} /$ day. This corresponds to a C/D ratio of $1.17(350 / 300)$. Therefore in the US, clozapine C/D ratios typically range between approximately 0.60 and $1.20 .^{[16]}$

Based on the limited published data on Chinese patients, ${ }^{[13-15]}$ and the fact that clozapine follows linear kinetics, the review ${ }^{16}$ also proposed that East Asians may have clozapine $\mathrm{C} / \mathrm{D}$ ratios that are twice as high, ranging from 1.20 to 2.40 , which means that they need only half the clozapine dosage of US Caucasians. ${ }^{[16]}$ In 2019 , a systematic review of clozapine levels supported that conclusion, ${ }^{[8]}$ since the clozapine $\mathrm{C} / \mathrm{D}$ ratio was higher when comparing weighted mean values of 1.57 in 876 East Asians and 1.07 in 1147 Caucasians $(P<0.001)$. Interestingly, a Mexican study ${ }^{[17]}$ which provided no information on patient ethnicity described clozapine C/D ratios similar to East Asians.

\section{THE EVIDENCE FROM CLOZAPINE DOSING IN ASIAN COUNTRIES}

In 1998, Farooq ${ }^{[18]}$ reported his clinical observation that Pakistani psychiatrists also used lower doses similar to those used by Chinese psychiatrists, and proposed that Pakistanis also have lower clozapine clearance than Caucasians, but similar to Chinese. However, these comments on the need for low clozapine doses in Chinese and Pakistani patients were largely ignored in Western countries.

Clozapine is widely used in China. In 2012, Wang and $\mathrm{Li}^{\left[{ }^{19]}\right.}$ stated that the mean dose reported in Chinese studies was $216 \mathrm{mg} /$ day, which was much lower than the $43 \mathrm{l} \mathrm{mg}$ /day reported in the non-Chinese literature. A dosing study with $>3,000$ samples from the Japanese clozapine database described a mean dose of $186 \mathrm{mg} /$ day. ${ }^{[20]}$ In a survey of 117 Indian psychiatrists, Shrivastava and Shah ${ }^{[21]}$ indicated that almost all (86\%) of their patients were stabilized on clozapine doses lower than $300 \mathrm{mg} /$ day. A recent Asian review described clozapine daily dosing in single samples from several different countries. In countries with no published blood levels, the sample average doses (in $\mathrm{mg} /$ day) were 368 in Sri Lanka, 364 in Malaysia, 245 in Thailand, 193 in Myanmar, 182 in Vietnam, 158 in Pakistan, 142 in Bangladesh and 58 in Indonesia. ${ }^{[22]}$

\section{DOSING RECOMMENDATION FOR ASIANS IN THE ABSENCE OF BLOOD LEVELS}

If the psychiatrist has access to blood levels, the best way to personalize clozapine dosing ${ }^{[23]}$ is to use a dose that provides a trough steady-state clozapine concentration of at least $350 \mathrm{ng} / \mathrm{ml} .{ }^{[24]}$ Alternatively, the data from the five Asian samples ${ }^{[25]}$ after sex and smoking stratification can be used to orient Asian clinicians who have no access to an assessment of blood levels. The five samples were from Beijing, ${ }^{[8,26]}$ Taipei, ${ }^{[27]}$ Seoul, ${ }^{[28]}$ and Vellore. ${ }^{[29]}$ In these 5 Asian samples, the clozapine dose required to reach at least $350 \mathrm{ng} / \mathrm{ml}$ in female non-smokers ranged from 145 to $189 \mathrm{mg} /$ day and in male smokers, from 259 to $294 \mathrm{mg} /$ day.

These clozapine dosing guidelines are based on patients with average metabolism who are not using inducers (other than smoking) or inhibitors and do not have extreme obesity. The dose needed for clinical response in Asian patients with average clozapine metabolism ranges between $150 \mathrm{mg}$ /day for female non-smokers and $300 \mathrm{mg} /$ day for male smokers. After reaching these doses, when a psychiatrist is faced with the need to ascertain whether the patient is not going to respond to clozapine, they may want to reach at least $200 \mathrm{mg} /$ day in an Asian female non-smoker before declaring her to be non-responsive; likewise, an Asian male smoker will need at least $350 \mathrm{mg} /$ day. Asian female smokers and Asian non-smoking males will need intermediate doses.

\section{THE IMPORTANCE OF USING CLOZAPINE BLOOD LEVELS IN ASIANS}

This review has so far focused on Asian non-smoking females or Asian smoking males with average metabolism, but not all patients are average for clozapine metabolism. Clozapine PMs and UMs exist, and they can be genetic or non-genetic PMs or UMs.

In the 5 Asian samples, ${ }^{[25]}$ approximately 10\% (range 2-13\%) of possible genetic clozapine PMs needed very low clozapine doses of approximately $50-125 \mathrm{mg} /$ day to reach $350 \mathrm{ng} / \mathrm{ml}$. In Vellore, the PM percentage appeared 
to be $2 \%$. Moreover, phenoconversion by environmental and personal variables can make a normal clozapine metabolizer appear to be a phenotypical clozapine PM. Fluvoxamine is an extremely powerful inhibitor of clozapine metabolism that makes most patients resemble clozapine PMs, ${ }^{[30]}$ and should never be co-prescribed with clozapine in the absence of access to blood levels. Other powerful inhibitors of clozapine metabolism that are likely to make a patient a clozapine PM are: ciprofloxacin, oral contraceptives, and high doses of caffeine. Phenothiazines, tricyclic antidepressants, and high doses of sertraline can also phenoconvert patients to clozapine PM. ${ }^{[30]}$ Valproic acid in some patients may also inhibit clozapine metabolism. ${ }^{[29,31]}$

More importantly, using the clozapine C/D ratio in the Vellore sample, we estimated that a clozapine PM male smoker who was taking valproic acid would only need $105 \mathrm{mg} /$ day to get therapeutic concentrations. ${ }^{[25]}$

Clozapine deposits in fat tissue ${ }^{[32]}$ and this decreases clozapine clearance. After combining four Asian samples with measures of weights, we found that 1.1\% (5/429) of patients appear to be phenotypic clozapine PMs due to extreme obesity. ${ }^{[25]}$

The most common cause of clozapine phenotypic PM status may be a severe infection or severe inflammation with systemic manifestations that include fever and/or elevations of C-reactive protein (CRP). The inflammation releases cytokines that inhibit CYP1A2 and other CYPs, thereby increasing clozapine levels. ${ }^{[33]}$ Most clinicians are not aware that pneumonia can be lethal in clozapine patients because it can lead to clozapine intoxication. ${ }^{[34]}$ Halving the clozapine dose when pneumonia is diagnosed, or when any serious inflammation/infection with fever and/or CRP elevation occurs, may avoid the development of clozapine intoxication. ${ }^{[3,34]}$ The complexities involved in diagnosing fever in clozapine patients are reviewed in a recent article. ${ }^{[35]}$

Patients taking a potent inducer such as rifampicin or one of the three potent antiepileptic inducers, phenytoin or phenobarbital, can become clozapine UMs and require much higher clozapine doses. ${ }^{[30]}$ Valproic acid, instead of being an inhibitor of clozapine metabolism, can be an inducer in some patients. Studies suggest that when valproic acid acts as an inducer, it mainly induces norclozapine metabolism ${ }^{[31,36-38]}$ but can sometimes contribute to the patient becoming a UM who needs very high clozapine doses. ${ }^{[39]}$ Norclozapine is clozapine's main metabolite and has no antipsychotic efficacy but may contribute to adverse drug reactions. ${ }^{[40]}$ In summary, in some clozapine patients, valproic acid can act as an inhibitor of clozapine metabolism and in others, as an inducer, particularly of norclozapine metabolism. ${ }^{[41]}$ During early titrations, it is important to consider the risk of inhibition.

Mild CYPIA2 inducers are omeprazole and intake of cruciferous vegetables such as broccoli. These latter compounds and the polycyclic aromatic hydrocarbons (PAH) found in the smoke of tobacco bind to the aryl hydrocarbon receptor (AhR), inducing CYP1A2 expression. ${ }^{[42]}$ The same PAH in barbecued food can act as it does in tobacco smoke, but one would have to consume great quantities of barbecued food to gain the same effect as daily smoking. More importantly, in people from India or Sri Lanka, ${ }^{[4]}$ high coffee intake has been associated with induction of CYP1A2 expression, possibly because of the way the coffee beans are roasted. Using the clozapine C/D ratio in the Vellore sample, we estimated that a particular clozapine UM would need $1029 \mathrm{mg} /$ day of clozapine to reach a clozapine level of $350 \mathrm{ng} / \mathrm{ml}$. She was a non-smoking female who reported consuming 10 cups of coffee/day, much higher than other patients. Assuming that her single clozapine level was not contaminated by lack of adherence, she appeared to be a clozapine UM explained by the high induction produced by the roasting of coffee beans. ${ }^{[25]}$

In conclusion, the best way of personalizing dosing for clozapine PMs and UMs, whether genetic or non-genetic by source, is to measure clozapine blood levels. ${ }^{[23]}$

\section{THE NEED FOR STARTING WITH LOWER DOSES AND SLOWER TITRATION IN ASIAN PATIENTS}

Asian patients need half the dose to which Caucasian patients are usually up-titrated. Therefore to prevent myocarditis, in Asians, it may be desirable to start with $12.5 \mathrm{mg} /$ day and, if tolerated, to reach $50 \mathrm{mg} /$ day at day $7,100 \mathrm{mg} /$ day at day 14 , and $150 \mathrm{mg} /$ day at day 21 . Then, after reaching a steady-state (five days later), a trough clozapine level could be obtained to personalize dosing. It is preferable to require a normal CRP level for starting clozapine, or else systemic inflammation-related reduction in clozapine metabolism may compromise the safety of the titration. ${ }^{[23,44]}$ Weekly CRP can be measured with the white blood count (WBC). If the CRP is elevated, clozapine should be stopped until the CRP normalizes because this may be an initial sign of clozapine-induced inflammation that can progress to myocarditis. ${ }^{[23,44]}$ Frequently, clozapine up-titration is conducted in the background of a prior antipsychotic, and so delaying clozapine titration until CRP normalizes is safe. If the patient is not already taking another antipsychotic, an additional antipsychotic can 
be given until it is determined that the patient can tolerate a slower clozapine up-titration.

Two articles have independently proposed that clozapine-induced myocarditis is a hypersensitive reaction similar to lamotrigine-induced Stevens-Johnson syndrome that is produced by rapid up-titration. ${ }^{[45,46]}$ Normal titration may lead to myocarditis in clozapine PMs, such as those taking valproic acid. ${ }^{47]}$ If the clozapine up-titration is too fast for a specific patient, a clozapine-induced inflammation will develop, manifested as CRP elevation. This will further reduce clozapine metabolism and predispose to myocarditis. The high incidence of clozapine-induced myocarditis in Australia may be partly explained by the use of Caucasian-level titration in patients of Asian ancestry, considering the increase in Asian emigration to Australia in the last ten years. ${ }^{[8]}$

\section{INTERPRETING CLOZAPINE BLOOD LEVELS}

Clinicians frequently fail to understand that a single clozapine level must be viewed with caution and that a pattern change across several levels is easier to interpret. Laboratory, technical, and natural variations can cause some day-to-day variations in clozapine levels, even after assuming the stability of all possible confounding factors such as trough (early morning before medication intake) and steady-state levels ( $\geq 5$ days with no clozapine dose change), drug interactions, smoking, and caffeine intake. ${ }^{[4]}$ The most important changes in clozapine levels in outpatients are due to a lack of compliance. ${ }^{[49]}$ Based on an RCT in an inpatient setting with very strict control over compliance and many levels every other week for months, ${ }^{[50]}$ we have suggested that only a change by a factor of 2 is probably meaningful from the clinician's perspective. This means that if an individual has a clozapine level of $500 \mathrm{ng} / \mathrm{ml}$, the next one under the same stable conditions should not be $>1000$ or $<250 \mathrm{ng} / \mathrm{ml}$. However, a change from 500 to $400 \mathrm{ng} / \mathrm{ml}$ is probably not significant. ${ }^{[48]}$

\section{CONCLUSION}

This review article proposes that Asians, defined as people whose ancestral origins range geographically from Pakistan to Japan, and who comprise up to $50 \%$ of the world's population, may need half the clozapine dosage used in Western countries. Psychiatrists in India, and more widely, in Asia, need to be aware that the clozapine doses needed by Asian patients are half those needed by Caucasian patients.

Based on the evidence presented in this article, Asian psychiatrists should encourage their hospitals and facilities, where possible, to developing laboratories that can allow obtaining clozapine levels to become routine practice. This would help personalize clozapine dosing. Asian pharmaceutical companies should consider developing clozapine formulations that allow lower doses, such as 12.5, 10, or even $5 \mathrm{mg}$. These low doses are far more appropriate for starting clozapine in Asian patients. This article estimates dosing for Asians based on linear kinetics and the estimation that the lower therapeutic range is $350 \mathrm{ng} / \mathrm{ml}$, but this value is mainly based on studies in Caucasians and response-plasma levels in Asians are needed. Future studies in Asian patients need to establish whether or not this value $(350 \mathrm{ng} / \mathrm{ml})$ needs to be modified in Asians.

\section{Acknowledgements}

The authors acknowledge Lorraine Maw, M.A., at the Mental Health Research Center at Eastern State Hospital, Lexington, KY, who helped in editing this article.

\section{Financial support and sponsorship Nil.}

\section{Conflicts of interest}

In the last 3 years, Drs. de Leon, Rajkumar, Kaithi, Schoretsanitis, Wang, Tang, Lin, Hong, Farooq, Ruan and Andrade have had no conflicts of interest. In the last 3 years, Dr. Kane reports personal fees from Alkermes, personal fees from Allergan, personal fees from Bristol-Myers Squibb, personal fees from IntraCellular Therapies, personal fees from Janssen, personal fees from Lundbeck, personal fees from Minerva, personal fees from Neurocrine, personal fees from Otsuka, personal fees from Pierre Fabre, personal fees from Reviva, personal fees from Sunovion, personal fees from Takeda, personal fees from Teva, other outside the submitted work from LB Pharma, MedAvante and The Vanguard Research Group. In the last 3 years, Dr. Ng reports being a consultant for Grunbiotics, Lundbeck, Servier, and Janssen-Cilag, and received research speaker honoraria from Servier, Janssen-Cilag and Pfizer.

\section{REFERENCES}

1. Marder SR, Yang YS. Clozapine. In: Schatzberg AF, Nemeroff CB, editors. The American Psychiatric Association Publishing textbook of psychopharmacology. $5^{\text {th }}$ edition. Washington, DC: American Psychiatric Association Publishing; 2017. p. 623-48.

2. Citrome L, McEvoy JP, Saklad SR. Guide to the management of clozapine-related tolerability and safety concerns. Clin Schizophr Relat Psychoses 2016;10:163-77.

3. Taylor DM, Barnes TR, Young AH. Maudsley Prescribing Guidelines in Psychiatry. $13^{\text {th }}$ ed. Hosbroken, $\mathrm{NJ}$ : Wiley-Blackwell; 2018. 
4. NICE. Psychosis and schizophrenia in adults: Prevention and management. Clinical guideline (nice.org.uk/guidance/ cg178).

5. de Leon J. Evidence-based medicine versus personalized medicine: Are they enemies? J Clin Psychopharmacol 2012;32:153-64.

6. Subramanian S, Völlm BA, Huband N. Clozapine dose for schizophrenia. Cochrane Database Syst Rev 2017;6:CD009555.

7. Ghotbi R, Christensen M, Roh HK, Ingelman-Sundberg M, Aklillu E, Bertilsson L. Comparisons of CYP1A2 genetic polymorphisms, enzyme activity and the genotype-phenotype relationship in Swedes and Koreans. Eur J Clin Pharmacol 2007;63:537-46.

8. Ruan CJ, Zang YN, Wang CY, Cheng YH, Sun C, Spina E, et al. Clozapine metabolism in East Asians and Caucasians: A pilot exploration of the prevalence of poor metabolizers and a systematic review. J Clin Psychopharmacol 2019;39:135-44.

9. Singh R, Teo YY. "Asian" phenotype underestimates the genetic diversity of Asia yet overstates its impact on variability in drug disposition and pharmacodynamics. Clin Pharmacol Ther 2019;105:802-5.

10. Nielsen R, Akey JM, Jakobsson M, Pritchard JK, Tishkoff S, Willerslev E. Tracing the peopling of the world through genomics. Nature 2017;541:302-10.

11. Taskent RO, Gokcumen O. The multiple histories of Western Asia: Perspectives from ancient and modern genomes. Hum Biol 2017;89:107-17.

12. Moorjani P, Thangaraj K, Patterson N, Lipson M, Loh PR, Govindaraj P, et al. Genetic evidence for recent population mixture in India. Am J Hum Genet 2013;93:422-38.

13. Chang WH, Lin SK, Lane HY, Hu WH, Jann MW, Lin HN. Clozapine dosages and plasma drug concentrations. J Formos Med Assoc 1997;96:599-605.

14. Chong SA, Tan CH, Khoo YM, Lee HS, Wong KE, Ngui F, et al. Clinical evaluation and plasma clozapine concentrations in Chinese patients with schizophrenia. Ther Drug Monit 1997;19:219-23.

15. Ng CH, Chong SA, Lambert T, Fan A, Hackett LP, Mahendran $\mathrm{R}$, et al. An inter-ethnic comparison study of clozapine dosage, clinical response and plasma levels. Int Clin Psychopharmacol 2005;20:163-8.

16. Spina E, de Leon J. Clinical applications of CYP genotyping in psychiatry. J Neural Transm (Vienna) 2015;122:5-28.

17. González-Esquivel DF, Castro N, Ramírez-Bermúdez J, Custodio V, Rojas-Tomé S, Castro-Román R, et al. Plasma levels of clozapine and norclozapine in Mexican schizophrenia patients. Arzneimittelforschung 2011;61:335-9.

18. Farooq S. Ethnicity and clozapine metabolism. Br J Psychiatry 1998;173:87.

19. Wang C, Li L. Proper use of clozapine: Experiences in China. Shanghai Arch Psychiatry 2012;24:108-9.

20. Inada K, Oshibuchi H, Ishigooka J, Nishimura K. Analysis of clozapine use and safety by using comprehensive national data from the Japanese Clozapine Patient Monitoring Service. J Clin Psychopharmacol 2018;38:302-6.

21. Shrivastava A, Shah N. Prescribing practices of clozapine in India: Results of a opinion survey of psychiatrists. Indian $\mathrm{J}$ Psychiatry 2009;51:225-6.

22. Xu SW, Dong M, Zhang Q, Yang SY, Chen LY, Sim K, et al. Clozapine prescription pattern in patients with schizophrenia in Asia: The REAP survey (2016). Psychiatry Res 2019 (in press) S0165-1781(18)32218-2.

23. de Leon J. Personalizing dosing of risperidone, paliperidone and clozapine using therapeutic drug monitoring and pharmacogenetics. Neuropharmacology. (in press). S0028-3908(19)30197-2. doi: 10.1016/j.neuropharm. 2019.05.033.

24. Hiemke C, Bergemann N, Clement HW, Conca A, Deckert J, Domschke $\mathrm{K}$, et al. Consensus guidelines for therapeutic drug monitoring in neuropsychopharmacology: Update 2017. Pharmacopsychiatry 2018;51:e1.

25. Ruan CJ, Wang CY, Tang YL, Lin SK, Lee ST, Hong KS, et al. Exploring the prevalence of clozapine phenotypic poor metabolizers in 4 Asian samples: They ranged between 2 and 13\%. J Clin Psychopharmacol. (in press). doI: 10.1097/ JCP.0000000000001125.

26. Tang YL, Mao P, Li FM, Li W, Chen Q, Jiang F, et al. Gender, age, smoking behaviour and plasma clozapine concentrations in 193 Chinese inpatients with schizophrenia. Br J Clin Pharmacol 2007;64:49-56.

27. Lin SK, Su SF, Pan CH. Higher plasma drug concentration in clozapine-treated schizophrenic patients with side effects of obsessive/compulsive symptoms. Ther Drug Monit 2006;28:303-7.

28. Lee ST, Ryu S, Nam HJ, Lee SY, Hong KS. Determination of pharmacokinetic properties of clozapine and norclozapine in Korean schizophrenia patients. Int Clin Psychopharmacol 2009;24:139-44.

29. Rajkumar AP, Poonkuzhali B, Kuruvilla A, Jacob M, Jacob KS. Clinical predictors of serum clozapine levels in patients with treatment-resistant schizophrenia. Int Clin Psychopharmacol 2013;28:50-6.

30. Spina E, Hiemke C, de Leon J. Assessing drug-drug interactions through therapeutic drug monitoring when administering oral second-generation antipsychotics. Expert Opin Drug Metab Toxicol 2016;12:407-22.

31. Diaz FJ, Santoro V, Spina E, Cogollo M, Rivera TE, Botts S, et al. Estimating the size of the effects of co-medications on plasma clozapine concentrations using a model that controls for clozapine doses and confounding variables. Pharmacopsychiatry 2008;41:81-91.

32. Diaz FJ, Josiassen RC, de Leon J. The effect of body weight changes on total plasma clozapine concentrations determined by applying a statistical model to the data from a double-blind trial. J Clin Psychopharmacol 2018;38:442-6.

33. de Leon J, Diaz FJ. Serious respiratory infections can increase clozapine levels and contribute to side effects: A case report. Prog Neuropsychopharmacol Biol Psychiatry 2003;27:1059-63.

34. de Leon J, Sanz EJ, De las Cuevas C. Data from the World Health Organization's pharmacovigilance database supports the prominent role of pneumonia in mortality associated with clozapine adverse drug reactions. Schizophr Bull. (in press). doi:10.1093/schbul/sbz093.

35. Verdoux H, Quiles C, de Leon J. Clinical determinants of fever in clozapine users and implications for treatment management: A narrative review. Schizophr Res 2019;211:1-9.

36. Diaz FJ, Eap CB, Ansermot N, Crettol S, Crettol S, Spina E, et al. Can valproic acid be an inducer of clozapine metabolism? Pharmacopsychiatry 2014;47:89-96.

37. Hommers L, Scharl M, Hefner G, Hohner M, Fischer M, Pfuhlmann B, et al. Comedication of valproic acid is associated with increased metabolism of clozapine. J Clin Psychopharmacol 2018;38:188-192.

38. Smith RL, Kyllesø L, Haslemo T, Andreassen OA, Molden E. Reduction in $\mathrm{N}$-desmethylclozapine level is determined by daily dose but not serum concentration of valproic acid-indications of a presystemic interaction mechanism. Ther Drug Monit 2019;41:503-8.

39. Riesselman A, Strobl B, Cooley AT, de Leon J. A case 
report that suggested that aspirin's effects on valproic acid metabolism may contribute to valproic acid's inducer effects on clozapine metabolism. J Clin Psychopharmacol 2013;33:812-4.

40. Schoretsanitis G, Kane JM, Ruan CJ, Spina E, Hiemke C, de Leon J. A comprehensive review of the clinical utility of and a combined analysis of the clozapine/norclozapine ratio in therapeutic drug monitoring for adult patients. Expert Rev Clin Pharmacol 2019;12:603-21.

41. de Leon J. Future studies on the interaction between clozapine and valproic acid should aspire to include longitudinal designs and free valproate concentrations, and should consider that inducer and/or inhibitory effects may vary with time, the individual and the auto-induction of valproic acid. Ther Drug Monit (in press). doi: 10.1097/ FTD.0000000000000705.

42. de Leon J. The effects of antiepileptic inducers in neuropsychopharmacology, a neglected issue. Part II: Pharmacological issues and further understanding. Rev Psiquiatr Salud Ment 2015;8:167-88.

43. Perera V, Gross AS, McLachlan AJ. Influence of environmental and genetic factors on CYP1A2 activity in individuals of South Asian and European ancestry. Clin Pharmacol Ther 2012;92:511-9.

44. de Leon J, Rhee DW, Kondracke A. Rapid titration and decreased clozapine clearance may help explain five cases of clozapine-induced myocarditis in a New York hospital. Psychosomatics (in press). doi: 10.1016/j. psym.2019.08.008.

45. Freudenreich O. Clozapine-induced myocarditis: Prescribe safely but do prescribe. Acta Psychiatr Scand 2015;132:240-1.

46. de Leon J, Tang YL, Baptista T, Cohen D, Schulte PF. Titrating clozapine amidst recommendations proposing high myocarditis risk and rapid titrations. Acta Psychiatr Scand 2015;132:242-3.

47. Chopra N, de Leon J. Clozapine-induced myocarditis may be associated with rapid titration: A case report verified with autopsy. Int J Psychiatry Med 2016;51:104-15.

48. Sabaawi M, Singh NN, de Leon J. Guidelines for the use of clozapine in individuals with developmental disabilities. Res Dev Disabil 2006;27:309-36.

49. Stieffenhofer V, Saglam H, Schmidtmann I, Silver H, Hiemke C, Konrad A. Clozapine plasma level monitoring for prediction of rehospitalization schizophrenic outpatients. Pharmacopsychiatry 2011;44:55-9.

50. Diaz FJ, de Leon J, Josiassen RC, Cooper TB, Simpson GM. Plasma clozapine concentration coefficients of variation in a long-term study. Schizophr Res 2005;72:131-5. 


\section{University Library}

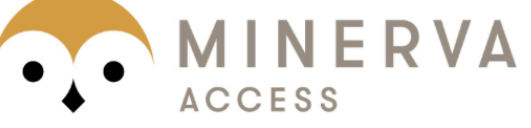

A gateway to Melbourne's research publications

Minerva Access is the Institutional Repository of The University of Melbourne

\section{Author/s:}

de Leon, J;Rajkumar, AP;Kaithi, AR;Schoretsanitis, G;Kane, JM;Wang, C-Y;Tang, Y-L;Lin, SK;Hong, KS;Farooq, S;Ng, CH;Ruan, C-J;Andrade, C

Title:

Do Asian Patients Require Only Half of the Clozapine Dose Prescribed for Caucasians? A Critical Overview

Date:

2020-01-01

\section{Citation:}

de Leon, J., Rajkumar, A. P., Kaithi, A. R., Schoretsanitis, G., Kane, J. M., Wang, C. -Y., Tang, Y. -L., Lin, S. -K., Hong, K. S., Farooq, S., Ng, C. H., Ruan, C. -J. \& Andrade, C. (2020). Do Asian Patients Require Only Half of the Clozapine Dose Prescribed for Caucasians? A Critical Overview. INDIAN JOURNAL OF PSYCHOLOGICAL MEDICINE, 42 (1), pp.4-10. https://doi.org/10.4103/IJPSYM.IJPSYM_379_19.

Persistent Link:

http://hdl.handle.net/11343/252326

License:

CC BY-NC-SA 